\title{
Energy Saving Cooling-Unit for Plastic Moulding Machine
}

\author{
Darko Lovrec1,* - Vito Tič 1,2 \\ 1 University of Maribor, Faculty of Mechanical Engineering, Slovenia \\ 2 Olma d.d., Slovenia
}

\begin{abstract}
Compressed air is one of the major sources of energy consumption and also one of the most expensive types of energy. Consequently, special attention must be paid to its rational use. This is especially important in cases where compressed air is blowed into an "empty" space. All cleaning and cooling processes using compressed air are typical examples of such applications. They are the most wasteful consumers of compressed air. Measures to minimize air consumption in such cases are presented in the paper.

The highly efficient cooling unit for plastic moulding machines has been designed and optimized based on CFD simulation, and then produced using RP/RM (Rapid Prototyping / Manufacturing) manufacturing technology. The developed and specially designed nozzle-system was used for cooling purposes during plastic canister manufacturing. The previously-used conventional cooling system had so far been recognized as the most wasteful compressed air consumer in the company. The newly-designed air-efficient cooling unit, with increased capacity for cooling air, allows for up to 50\% energy savings regarding compressed air.
\end{abstract}

(C) 2011 Journal of Mechanical Engineering. All rights reserved.

Keywords: compressed air, cooling, blow moulding machine

\section{INTRODUCTION}

Compressed air is one of the major sources of energy consumption both in industry and its accompanying activities, and can be found in almost every factory. Compressed air powers a variety of equipment, including machine tools, material-handling and separation equipment, and spray-painting equipment. It is most often used in factories for cleaning, polishing, lacquering, air cleaning, drying etc. It is used in drilling, turning and forging processes in assembly plants in order to carry out material handling in combination with control techniques. It is indispensable in tyrevulcanizing services, and many other applications. The area using compressed air is very broad, and examples are very diverse.

Among other things, compressed air is used for cooling either tools or products in many technical processes - in spite of the fact that using compressed air for the cooling of parts is energetically ineffective. In metal or plastic machining processes, compressed air can be used e.g. for saw blades cooling of or for highefficient HM or HSS milling cutters. It can also be used with tools, which should not be cooled with coolant or e.g. when machining plastic products such as the cutting of pipes. During high-speed cutting the saw's blade should be cooled with air rather than water or a cooling emulsion because they can harm the material. With air cooling, a longer lifetime of the saw blade can be expected as well as better surface quality.

In all the cases mentioned, the cooling effect can be continuously, variably, or individually adjusted according to the required application. Nevertheless, the use of compressed air for cooling purposes is considered to be very uneconomical.

In compressed air systems the cost of energy is extremely high since normally a lot of unused heat is released, indicating that air is a very expensive type of energy [1]. Therefore, great effort is invested in reducing these costs and losses that occur along the entire route of the energy conversion, from electrical to the place where it is used for useful work (Fig. 1).

Due to its many losses compressed air is one of the most expensive types of energy, produced from electricity.

Modern compressed air systems typically convert only $20 \%$ of the consumed energy into mechanical work, while $80 \%$ of the energy

*Corr. Author's Address: University of Maribor, Faculty of Mechanical Engineering, 
consumed is dissipated in form of heat losses. Compressed air needs to be properly prepared (filtering, drying, reducing air pressure level), and if the device is poorly maintained, only $5 \%$ of the $100 \%$ electrical energy consumed is converted into mechanical work.

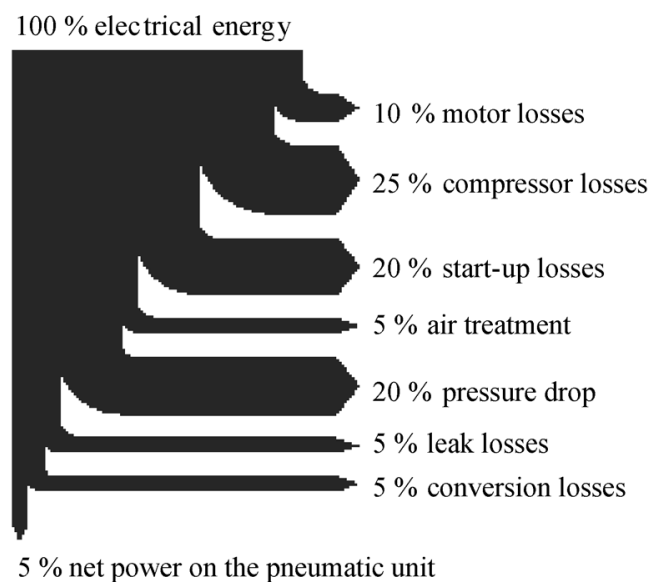

Fig. 1. Energy flow in a compressed air system

Air-leakages represent a particular problem in compressed air transport along the pipelines. The magnitude of this energy loss varies with the size and number of holes in the pipeline and on the machine - e.g. a small $3 \mathrm{~mm}$ hole causes 1000 euro annual loss, and a $6 \mathrm{~mm}$ hole will cause approx. 4500 euro of annual loss (at 6 bar). Sufficient facts indicate that special care must be taken when planning a compressor station, preparing air, and providing leakage-free air distribution. The leftover energy must be used in the most considered and rational way: these 5\% needs to be dealt with rationally. This is especially important in cases where compressed air is blown into free space. All cleaning and cooling processes using compressed air are typical examples of such applications and they represent the most wasteful consumers of compressed air. This indicates that focus on measures to minimize compressed air consumption in such applications is needed.

\section{COMPRESSED AIR ON PLASTIC BLOW-MOULDING MACHINES}

Compressed air is also used on plastic blow-moulding machines. Blow-moulding, also known as blow-forming, is a manufacturing process where hollow plastic parts are formed. In general, there are three main types of blowmoulding: injection blow-moulding, stretch-blow moulding and extrusion blow-moulding [2].

The blow-moulding process begins with the conventional extrusion of a parison or tube, using a die, similar to the one used for making plastic pipes. The parison is commonly extruded downwards between the two halves of an open blow-mould (Fig. 2). When the parison reaches the proper length, the mould closes, catching and holding the neck-end open, and pinching the bottom-end closed. A rod-like blow pin is inserted into the neck-end of the hot parison to simultaneously form the threaded opening and to inflate the parison inside the mould cavity using compressed air, then pressing it against a mould cavity. The pressure is held until the plastic cools. After the form cools, the mould opens to eject the bottle. Blow-moulding is often used to produce plastic vessels and containers, plastic bottles, canister, jugs, barrels, other containers, etc.

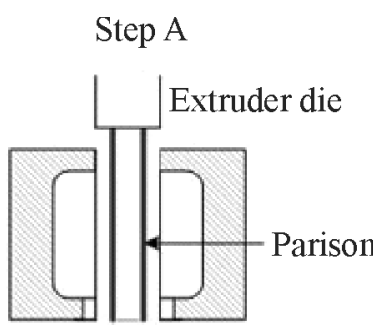

Step B
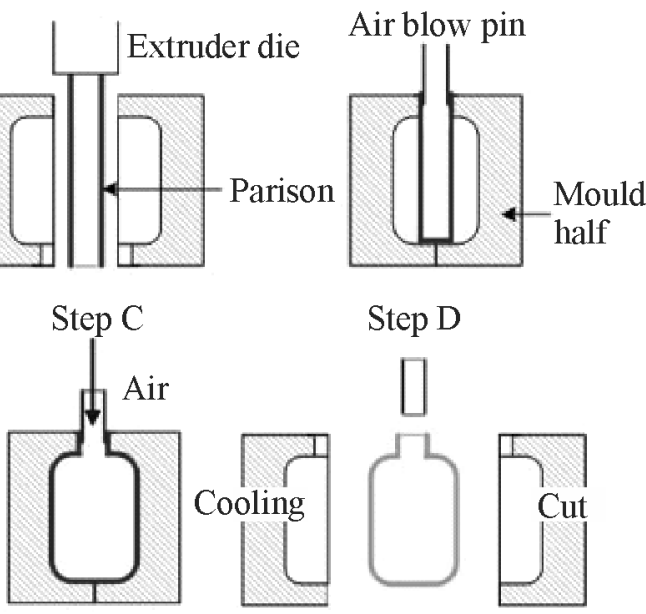

Step D

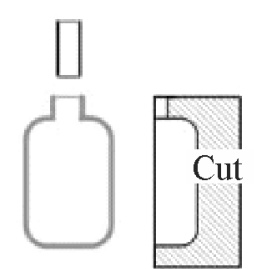

Fig. 2. Phases of extrusion blow-moulding processes

After the extrusion process, it is only necessary to remove the residues from the bottom of the plastic vessel, or residue from the throat and, in the case of canisters, the plastic rests under and above the handles. 
These is carried out after cooling of the mentioned canisters' parts at a special workplace (machine works in processing tact - cooling and cutting of residues is done simultaneously with blowing next canister) [3].

Fig. 3 shows the appearance of the discussed plastic canister as the end-product, areas of hot plastic above and below the handle, which must be removed, showed in an infra-red spectrum (as seen using a thermal camera) [4]. The picture also shows the existing cooling unit.
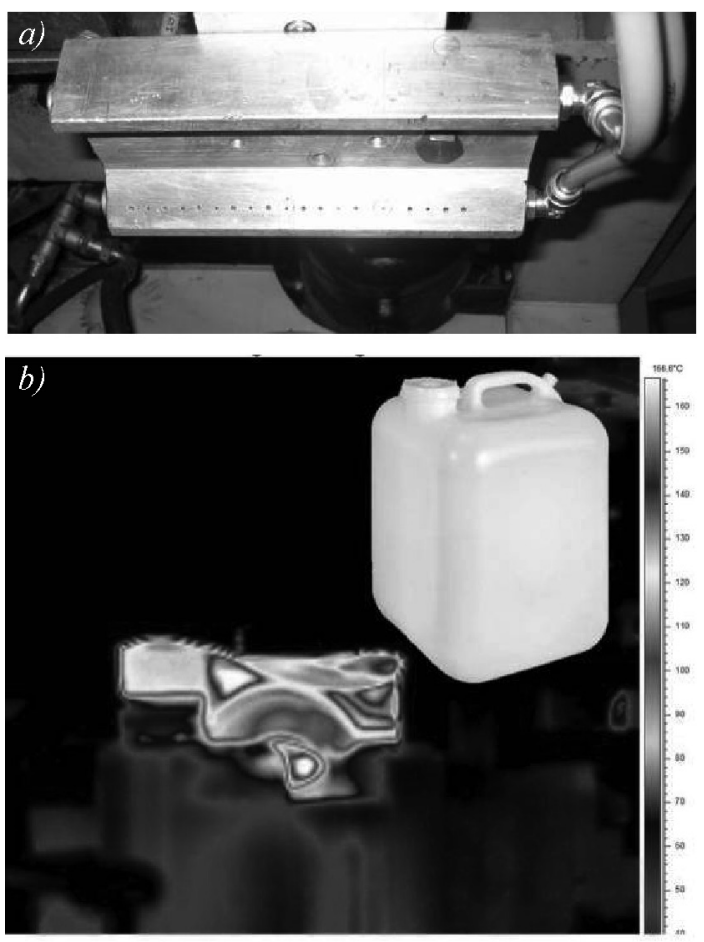

Fig. 3. Plastic canister - fields of hot plastic during cooling process; a) existing cooling-unit and b) temp. scale: 28 to $166^{\circ} \mathrm{C}$

Using the thermal camera captured image the already cooled canister-body (water cooling in the tool) and the hot material surpluses (residual of blow-moulding process) can be clearly seen. Cutting area of the canister must be cooled-down to a suitable temperature before cutting: from approximately 170 to $180{ }^{\circ} \mathrm{C}$, to a temperature which ensures the required hardness of the material for faultless cut (without damage to the product), which is about 135 to $138^{\circ} \mathrm{C}$.
The cooling process is performed using a simple cooling unit with multiple nozzles, as shown in Fig. 3, which consumes a large amount of compressed air - the cooling phase lasts approx. $15 \mathrm{~s}$, with compressed air consumption of $48 \mathrm{~m}^{3} / \mathrm{h}$. Such energy wasteful cooling systems in the plastic industry should be redesigned [5].

\section{DESIGN OF ENERGY-SAVING COOLING-UNIT}

Air blow-nozzles (e.g. in blow-guns) are one of the main consumers of compressed air in industry. Depending on the process and its requirements, a large amount of air is blown-out. This high consumption of air is not only highly expensive, but can also cause huge pressure drops in the pneumatic system - malfunctions.

Common blown-guns with classical nozzles work on the principle: "What comes in must come out". In the case of air-saving nozzles, it is not necessarily always so.

\subsection{Energy-Saving Nozzles - Theoretical Background}

Energy-saving nozzles work on the "Venturi nozzles" principle with side inlets. The operating principle is based on the Bernoulli and Continuity equation. By reducing the nozzle crosssection, the speed increases, and consequently the pressure is reduced all the way to vacuum, so that the surrounding air is sucked through the side-openings. The additional air sucked from the ambient does not have to be compressed. This means that the blow-gun is blowing out more air than it is actually consuming - see Fig. 4.

Example "Type A" represents air consumption of the ordinary blow-gun with classical nozzle, while example "Type B" shows air consumption of an energy-saving nozzle. Savings in compressed air consumption are approximately $40 \%$, in some cases even more (by lower input pressures).

In order to achieve the maximal efficiency of such a nozzle (the smallest amount of air entering and maximal leaving) the inside shape of the nozzle must be appropriately designed: flow conditions must be optimized to ensure maximal suction effect. 


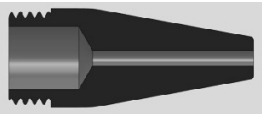

Type A:

Classical nozzle

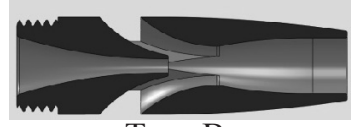

Type B:

Energy-saving nozzle

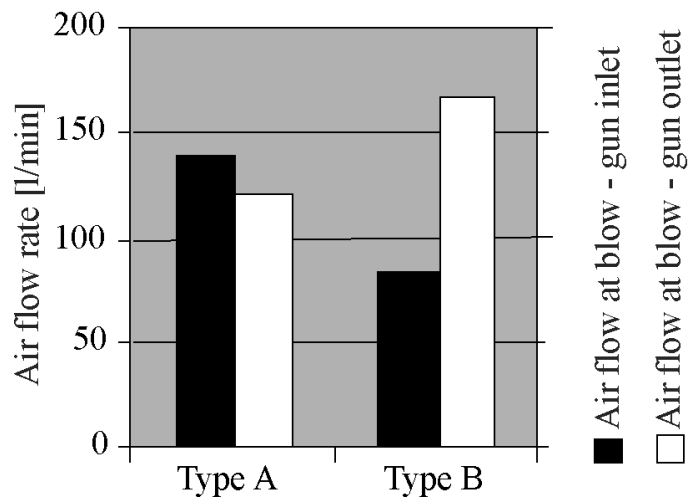

Fig. 4. Air consumption of different blow-nozzles at an operating pressure $4.5 \mathrm{bar}$

The optimal nozzle geometry (in terms of the most effective sucking from the surrounding air) is designed based on the corresponding mathematical model, and numerical simulations of air-flow through the nozzle. Simulations were carried out using the ANSYS Workbench program package [6].

\subsection{Meshing}

Numerical simulation is based on the finite-volumes method (FVM). The calculation area is a 3D volume, closed from all sides. The area is divided into tetrahedrons. Such a tetrahedron is called a flow-element, and its edges represent the calculating nodes. This type of mesh is a non-structured mesh. The location of the nodes is determined by the Cartesian coordinates $x, y$, and $z$. The dependent variables of pressure, velocity, turbulent kinetic energy, dissipation of the turbulent kinetic energy and the volume fraction are calculated for each node of the flowelement [7].

Surface and volume mesh were automatically created using Ansys CFX-Mesh with regard to additional settings. The mesh was refined near each narrowing in order to obtain more realistic simulation results [8] and [9].

Also, five inflation layers were created - the near solid wall's boundary layers affect velocity gradients, which are maximal in the normal direction to the wall.

\subsection{Simulation Model}

Most industrial flows include turbulent structures that cannot be resolved numerically on currently available computers. In order to overcome these limitations, computational fluid dynamics (CFD) methods solve the Reynolds averaged Navier-Stokes equations, using turbulence models to compute the averaged turbulent stresses. These models often limit the accuracy of CFD simulations [10].

The standard $k-\varepsilon$ model is used in the prediction of most turbulent flow calculations because of its robustness, economy, and reasonable accuracy over a wide range of flows. However, this model performs poorly when faced with non-equilibrium boundary layers. It tends to predict the onset of separation too late, as well as to underestimate the amount of separation. Separation influences the overall performances of many devices, such as diffusers, turbine blades and aerodynamic bodies. Separation also has a strong influence on other effects, such as wall heat transfer and multi-phase phenomena. Predicting reduced separation usually results in an optimistic prediction of machine performance. In some applications, this can have dangerous consequences, a notable example being the prediction of wing-stall on airplanes [10].

New models have been developed in order to solve this problem. One of the most effective is the shear-stress transport (SST) model. This model works by solving a turbulence/frequency-based model $(k-\omega)$ at the wall, and $k-\varepsilon$ in the bulk flow. A blending function ensures a smooth transition between the two models.

One of the advantages of the $k-\omega$ formulation is the near-wall treatment for lowReynolds number computations. The model does not involve the complex non-linear damping functions required for the $k-\varepsilon$ model and is, therefore, more accurate and more robust. A low-Reynolds $k-\varepsilon$ model would typically require a near-wall resolution of $y+<0.2$, while a lowReynolds number $k-\omega$ model would require at least $y+<2$. In industrial flows, even $y+<2$ cannot be guaranteed in most applications and for this 
reason a new near-wall treatment was developed for the $k-\omega$ models. It allows for smooth shift from a low-Reynolds number form to a wall function formulation [6].

The $k-\omega$ models assume that the turbulence viscosity is linked to the turbulence kinetic energy and turbulent frequency via the relationship:

$$
\mu_{t}=\rho \frac{k}{\omega}
$$

The $k-\omega$ based SST model accounts for the transportation of the turbulent shear-stress and gives highly accurate predictions of the onset and the amount of flow-separation under adverse pressure gradients. The Baseline $k-\omega$ model combines the advantages of the Wilcox and the $k-\varepsilon$ model, but still fails to properly predict the onset and amount of flow-separation from smooth surfaces. The main reason is that both models do not account for the transportation of turbulent shear-stress. This results in an overestimation of the eddy-viscosity. Proper transport behaviour can be obtained by a limiter to the formulation of the eddy-viscosity:

$$
v_{t}=\frac{a_{1} k}{\max \left(a_{1} \omega S F_{2}\right)},
$$

where

$$
v_{t}=\frac{\mu_{t}}{\rho} .
$$

Again $F_{2}$ has a blending function similar to $F_{1}$, which restricts the limiter to the wall boundary layer, as the underlying assumptions are incorrect for free shear-flows. $S$ is an invariant measure of the strain rate.

The blending functions are critical to the success of this method. Their formulation is based on the distance to the nearest surface, and on the flow variables:

$$
F_{1}=\tanh \left(\arg _{1}^{4}\right)
$$

with:

$$
\arg _{1}=\min \left(\max \left(\frac{\sqrt{k}}{\beta^{\prime} \omega y}, \frac{500 v}{y^{2} \omega}\right), \frac{4 \rho k}{C D_{k w} \sigma_{\omega 2} y^{2}}\right),
$$

where $y$ is the distance to the nearest wall, $v$ is the kinematic viscosity and:

$$
\begin{gathered}
C D_{k \omega}=\max \left(2 \rho \frac{1}{\sigma_{\omega 2} \omega} \nabla k \nabla \omega, 1.0 \times 10^{-10}\right), \\
F_{2}=\tanh \left(\arg _{2}^{2}\right),
\end{gathered}
$$

with:

$$
\arg _{2}=\max \left(\frac{2 \sqrt{k}}{\beta^{\prime} \omega y}, \frac{500 v}{y^{2} \omega}\right)
$$

Further information on the SST model can be found in literature [2].

The energy saving-nozzle was developed on the basis of the process described above. Internal geometry of the nozzle was optimized based on the air-flow simulations, and is shown in Fig. 5. Air was modelled as compressible gas with constant properties at $25^{\circ} \mathrm{C}$. Heat transfer was neglected at this stage of research.

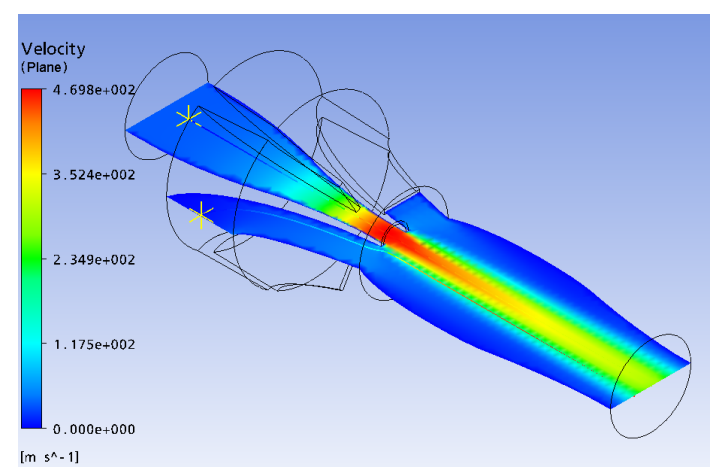

Fig. 5. CFD simulation result of nozzle

\subsection{Design of Energy-Saving Cooling-Unit}

A similar approach was to design the energy-saving cooling-unit. Compared to the relatively simple geometry of the nozzle, the geometry of the cooling-unit is definitely more complicated and complex.

The basic idea of the cooling-unit design was to connect series of nozzles in line with a single outlet's joint to a common outlet manifold. A crosssection of the cooling-unit geometry (at the nozzle) with expected flow conditions is shown in Fig. 6. 

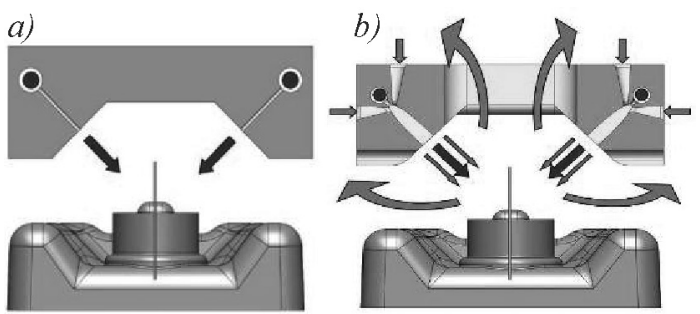

Fig. 6. Cross-section a) of existing cooling-unit, b) new cooling-unit with additional openings for better warm air disposal

The mesh results of the cooling unit are shown in Fig. 7 and presented in Table 1.

Table 1. Meshing - number of nodes and elements

\begin{tabular}{|l|c|c|}
\hline & Nodes & Elements \\
\hline $\begin{array}{l}\text { Existing cooling-unit } \\
\text { model }\end{array}$ & 520881 & 2594125 \\
\hline $\begin{array}{l}\text { New energy-saving unit } \\
\text { model }\end{array}$ & 680601 & 3576040 \\
\hline
\end{tabular}

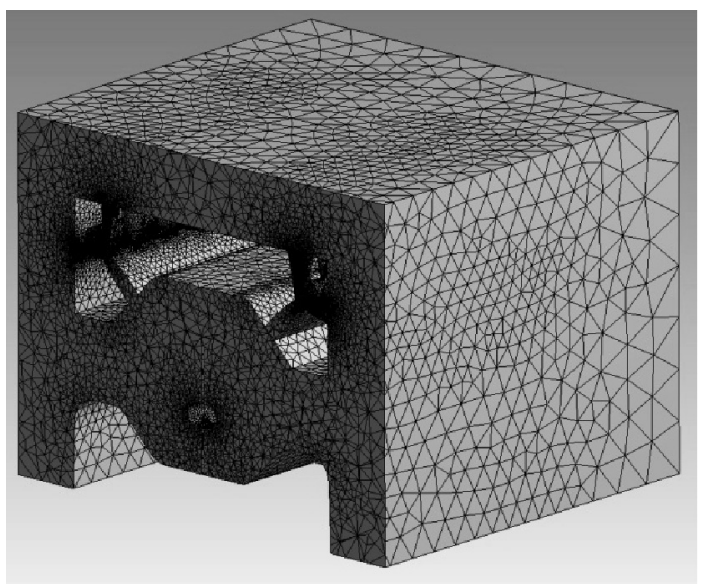

Fig. 7. Generated mesh of new energy-saving cooling-unit model

Following Figs. 6 and 7, the air-flow simulations results with convergence level of $1 \times 10^{-5}$ are shown in Fig. 8. They show 2D forward velocity streamlines on a cutting-plane starting from vertices with a time limit of $0.01 \mathrm{~s}$. The rainbow colour range is used from gray 0.0 $\mathrm{m} / \mathrm{s}$ to black $100 \mathrm{~m} / \mathrm{s}$. Simulated air-flow during the cooling phase is shown in Fig. 8: flow of fresh air in place from the cooling nozzles, sucking the surrounding air through side inlets and disposing of the warm air after cooling. Simulation results show a $45 \%$ increase in air mass-flow at the outlet manifold compared to the existing cooling-unit.

\subsection{Manufacturing Method for the Energy- Saving Cooling-Unit}

The shape and internal geometry of the nozzle were defined with development and optimization of the cooling-unit. The problem remaining was the construction of this form. This is usually where things come to a standstill, as complex forms require the use of complex and expensive manufacturing procedures. In case simpler form and construction is used (lower costs) the effect of the nozzle is not optimal. This is particularly true in the case of very complex form of the cooling-unit.

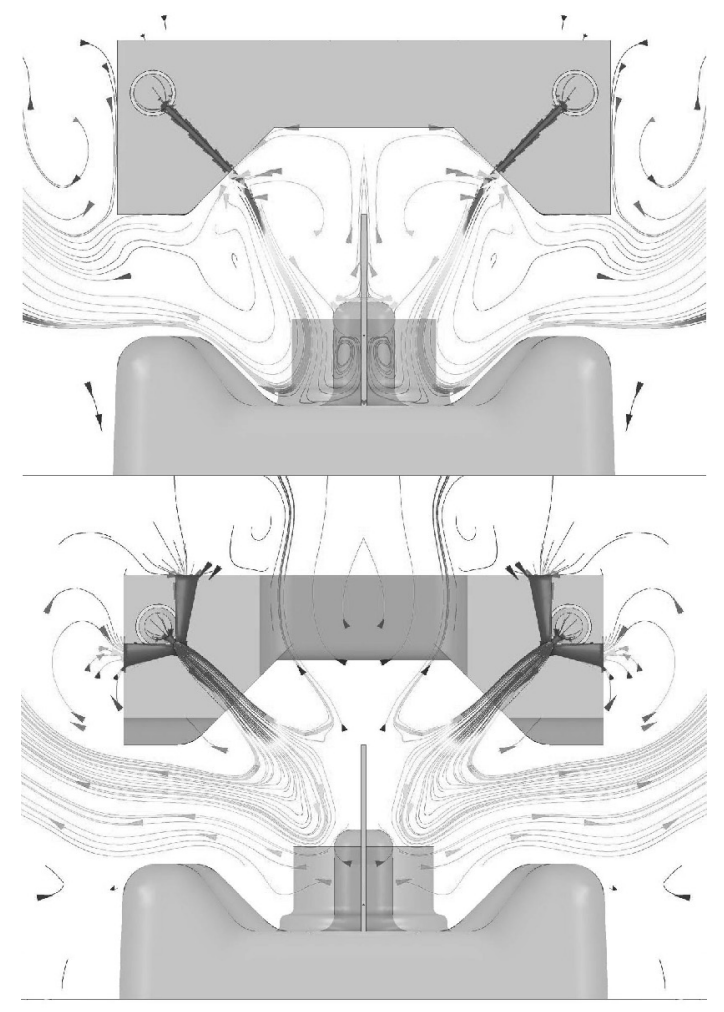

Fig. 8. Simulated air-flow in the existing coolingunit (above) and with optimized geometry design in the new cooling-unit (below)

With the use of Rapid Prototyping/ Manufacturing Technology (RP/RM) two good 
things can be combined - complex geometry of the nozzles with low manufacturing costs.

For experimental verification of effectiveness, the energy saving cooling-unit was produced by the rapid prototyping method using SLS technology (Selective Laser Sintering). As material, polyamide PA2200 in 30 micrometer granulation is used. The high-power laser $\left(\mathrm{CO}_{2}\right.$ laser) sticks together fine particles of plastic powder into layers that finally form a 3D object [11]. The final product made from this material has sufficient strength, is thermally stable, and has low weight.

\section{EXPERIMENTAL TESTING OF COOLING-UNIT EFFICIENCY}

It is reasonable to use a thermal camera to experimentally determine the efficiency of a newly-developed energy-saving coolingunit. With the help of a thermal imaging system the process of cooling the canister waste can be recorded and observed in detail. In order to determine the effectiveness of the cooling, the maximum temperature of the plastic, which still provides a flawless material cut, must be determined in conjunction with a reduction of compressed air consumption from the pneumatic network's supply.

The existing system, without the optimization of nozzle geometry and without the possibility of sucking surrounding air, uses $48 \mathrm{~m}^{3} / \mathrm{h}$ of compressed air, while the temperature of the cooled material ranges between 134 and $135{ }^{\circ} \mathrm{C}$. At higher temperatures, which may arise due to the lack of cooling efficiency, e.g. due to lower input quantities of compressed air, the plastic is insufficiently cooled and may lead to bad material cut - useless product.

The key factor regarding product quality is, therefore, the sufficiently low temperature of the plastic before cutting surpluses with minimum consumption of compressed air - whether cooling air is fully provided from a pneumatic network or the amount provided from a network is smaller, and the additional quantity is sucked from coolingunit's surrounding.

Temperature conditions at the given measured flow-rates of compressed air at the inlet of the cooling-unit are shown in Fig. 9 (in black white to provide better clearness). In all cases, the temperature fields were recorded during the finalstages of cooling process, immediately before the waste cut.
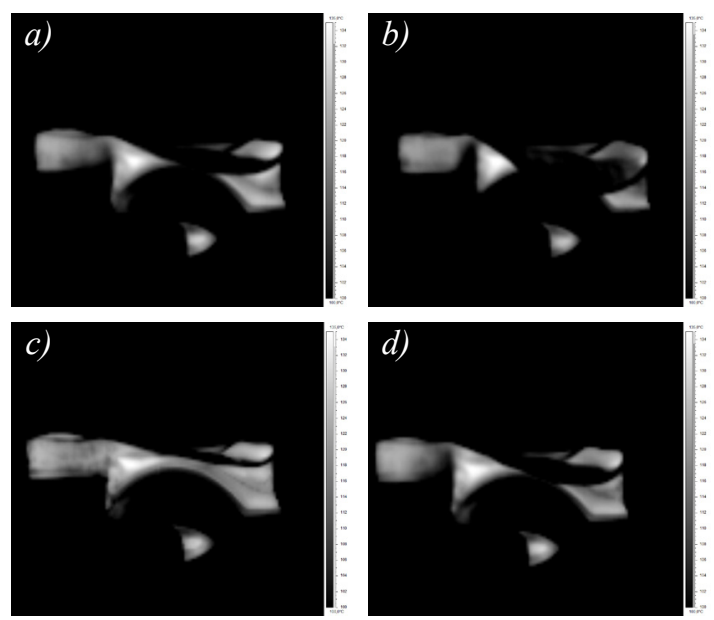

Fig. 9. Comparison of temperature fields of a) existing cooling-unit at flow of $48 \mathrm{~m}^{3} / \mathrm{h}, \mathrm{b}$ ) new cooling-unit at flow of $48 \mathrm{~m}^{3} / \mathrm{h}, \mathrm{c}$ ) existing cooling-unit at flow of $25 \mathrm{~m}^{3} / \mathrm{h}, d$ ) new coolingunit at flow of $25 \mathrm{~m}^{3} / \mathrm{h}$; temperature scale: 100 to $140{ }^{\circ} \mathrm{C}$

When comparing the thermal images of the waste materials temperature fields it is fairly clear, that cooling with the new cooling-unit is much more effective than with the old unit (Figs. 9a and $b$ ). The new cooling-unit consumes (almost) only half the compressed air for equally-effective cooling as the existing one (Figs. 9a and d). The remaining amount of air involved in the cooling was sucked "free" from the surrounding.

\section{DISCUSSION}

The principle used in an energy-saving nozzle, as an example of a simple element, was transferred to a more complex product - an energy-saving cooling-unit with a much more complex geometry.

The efficiency of this cooling-unit is clearly visible based on the thermo-graphic measurements and comparison of different inlet flows of compressed air from the pneumatic network. 
Despite current performance, there are many possibilities for further development of this system with regard to its greater efficiency, e.g. concentrated cooling at points with larger amount of material, cut-line aimed cooling instead of cooling the whole waste, production of a lightweight unit (honeycomb) with possible significant material savings and faster RP/RM manufacturing process and, therefore, lower product price, thus optimizing the geometry of cooling-unit for specific shapes, ..., are just some of the possible further development activities for such a cooling-unit. This is reasonable only in cases where compressed air is available on the machine and is already in use.

The presented cooling of waste material in the process of plastic-blowing is just one of the many possible examples of using such cooling, which can be designed much more efficiently when taking additional measures.

\section{SYMBOLS}

$k \quad$ turbulence kinetic energy per unit mass

$S \quad$ invariant measure of the strain rate

$y \quad$ distance to the nearest wall

$y+\quad$ dimensionless distance from the wall

$\beta \quad$ coefficient of thermal expansion

$\mu_{t} \quad$ turbulent viscosity

$v \quad$ kinematic viscosity

$\rho$ density

$\sigma \quad$ turbulence model constant

$\omega \quad$ angular velocity

\section{REFERENCES}

[1] Trautmann. A., Meyer, J., Herpertz, S. (2002). Rationelle Energienutzung in der Kunststoff verarbeitenden Industrie. Friedr. Vieweg\&Sohn Verlagsgesellschaft, Braunschweig/Wiesbaden.

[2] deLorenzi, H.G., Nied, H.F. (1987). Blow molding and thermoforming of plastics: Finite element modelling. Computers \& Structures, vol. 26, no. 1-2, p. 197-206.
[3] Bendada, A., Erchiqui, F., Kipping, A. (2005). Understanding heat transfer mechanisms during the cooling phase of blow molding using infrared thermography. NDT \& E International, vol. 38, no. 6, p. 433-441.

[4] Prystay, M., Wang, H., Garcia-Rejon, A. (1996). Application of thermographic temperature measurements in injection molding and blow molding of plastics. Proc. SPIE, vol. 2766: Thermosense XVIII: An International Conference on Thermal Sensing and Imaging Diagnostic Applications, Orlando.

[5] Glen, R., Anderson, R.G. (2006). Redesigning process cooling system in the plastics industry. Proceedings of the $28^{\text {th }}$ Industrial Energy Technology Conference, New Orleans.

[6] ANSYS CFX-Solver Theory Guide (2009). Ansys Inc., USA.

[7] Biluš, I., Škerget, L., Predin, A., Hriberšek, M. (2005). Experimental and numerical analyses of the cavitational flows around a hydrofoil. Strojniški vestnik - Journal of Mechanical Engineering, vol. 51, no. 2, p. 103-118.

[8] Berg, E., Volmajer, M. (2003). Validation of a CFD model for coupled simulation of nozzle flow, primary fuel jet break-up and spray formation. Proceedings of ICESO3, Salzburg, p. 1-10.

[9] Warsi, Z.U.A. (2005). Fluid Dynamics: Theoretical and Computational Approaches, $3^{\text {rd }}$ Edition. CRC Press.

[10] ANSYS (2006). Innovative Turbulence Modelling: SST Model in ANSYS® CFX. Ansys Inc., USA.

[11] Drstvenšek, I., Lovrec, D., Tič, V., Burjek, A., Jelovčan, L. (2008). Implementation of rapid manufacturing techniques for fluid power products. Ventil, vol. 14, no. 5, p. 476-482. 